\title{
DIFERENTES TIPOS DE APRENDIZAGEM
}

Yves J.J.M.R. de La TAILLE*

O objetivo de minha fala é o de situar a aprendizagem de valores éticos entre as várias propostas pedagógicas que são objeto da Educação Infantil. Nota-se que, em várias instituições de Educação Infantil, são feitos grandes e belos investimentos em aprendizagem de ciências (pequenos projetos), da arte (olhar e copiar quadros de Mestres), de matemática, de alfabetização, e de esporte (via brincadeiras, como pular corda). Todavia, o tema dos valores éticos costuma estar ausente. Ora, existe um tema, que é da infância, e que pode servir de aproximação alegre ao referido tema: as virtudes. Desenvolveremos este tema, com exemplos de pesquisa psicológica e reflexões sobre valores.

\section{NOTA}

1. Mesa Redonda "Educação Infantil: diferentes tipos de aprendizagem".

ENDEREÇO: Yves Joel Jean Marie Rodolpho de La Taille Instituto de Psicologia - USP

Av. Prof. Mello Moraes, 1721

05508-900 - São Paulo - SP BRASIL

\footnotetext{
* Instituto de Psicologia da Universidade de São Paulo.
} 